Research Article

\title{
Experimental and Numerical Studies on the Negative Flexural Behavior of Steel-UHPC Composite Beams
}

\author{
Xinhua Liu $\mathbb{D}^{1,2}$ Jianren Zhang, ${ }^{2}$ Zihan Cheng, ${ }^{3}$ and Meng $\mathrm{Ye}^{3}$ \\ ${ }^{1}$ CCCC Second Highway Consultants Co., Ltd., Wuhan 430056, China \\ ${ }^{2}$ College of Civil Engineering, Changsha University of Science \& Technology, Changsha 410114, China \\ ${ }^{3}$ College of Civil Engineering, Hunan University, Changsha 410082, China
}

Correspondence should be addressed to Xinhua Liu; h2112xh@163.com

Received 30 June 2020; Revised 4 January 2021; Accepted 21 January 2021; Published 31 January 2021

Academic Editor: Filippo Ubertini

Copyright ( $\odot 2021$ Xinhua Liu et al. This is an open access article distributed under the Creative Commons Attribution License, which permits unrestricted use, distribution, and reproduction in any medium, provided the original work is properly cited.

\begin{abstract}
The cracking of concrete in the negative moment region for a composite beam subjected to a negative bending moment reduces the beam's strength and stiffness. To improve the cracking performance of composite beams, this paper presents an experimental investigation on applying ultrahigh-performance concrete (UHPC) instead of conventional concrete. Three steel-UHPC composite beams with different forms of joints were designed and tested through a unique rotation angle loading method using a spring displacement control testing setup. The crack distribution, rotation versus crack width, load versus spring displacement, and strains in the UHPC slab and steel girders were measured and studied. Nonlinear finite element analysis using ABAQUS based on the damaged plasticity model of concrete was carried out for comparison with the test results. The experimental and numerical results showed that the use of a UHPC slab can enhance the cracking performance of composite beams. Considering the convenience of construction, a reasonable joint form was suggested, and the appropriate UHPC longitudinal laying length in the negative moment region was proposed to be $0.1 \mathrm{~L}$. Furthermore, a simplified formula for calculating the UHPC crack width was developed based on bond-slip theory.
\end{abstract}

\section{Introduction}

Steel-concrete composite bridges have been widely used in highways and urban construction due to their advantages of a light weight, excellent seismic performance, and quick construction. The construction method of erecting simply supported steel girders and then casting a continuous concrete slab on a multispan structure is often used in constructing small- and medium-span composite bridges. However, concrete slabs are liable to crack under service loads since the composite beam is subjected to a negative bending moment at the internal supports. The occurrence of cracks leads to a decrease in the stiffness and durability of a composite beam. Therefore, a key aspect of the mechanical properties of composite beams is the cracking resistance of concrete slabs in the negative moment region.

A series of studies have investigated the mechanical behavior of composite beams in the negative moment region. Chen [1] performed an experimental study on composite beams with external tendons in negative moment regions; they found that in hogging moment regions, adding prestressing to the composite beams with external tendons can effectively increase the cracking resistance of the beams. Ryu et al. [2] conducted an experimental test of two-span continuous composite girders with prefabricated slabs under a negative bending moment to study crack control and found that the initial crack spacing of the slab in a composite girder with prefabricated slabs can be wider than those of general reinforced concrete (RC) beam structures.

In recent years, researchers have tried to apply highperformance materials to improve the cracking behavior of structures. Alfarabi et al. [3] presented an experimental investigation into the use of carbon fibre-reinforced polymer (CFRP) in the negative moment region of continuous composite girders and confirmed the effectiveness of CFRP sheets in preventing crack initiation. In recent years, several 
studies [4-6] have been performed to investigate the behavior of steel fibre reinforced concrete (SFRC) beams. It was reported that SFRC has developed as an option to mitigate the unfavorable cracking characteristics of normal concrete due to the ability of the fibres to increase postcracking behavior and energy-absorbing capacity. In addition, the recent development of ultrahigh-performance concrete (UHPC) offers an attractive solution for improving the mechanical properties of composite beams in the negative moment region. Zhang et al. $[7,8]$ investigated the flexural behavior of damaged RC bridge deck strengthened by the UHPC layer.

UHPC is an advanced cementitious material that exhibits excellent compressive and tensile mechanical behaviors and great durability properties. UHPC has a compressive strength over $150 \mathrm{MPa}$ and a tensile strength over $7 \mathrm{MPa}$, and UHPC exhibits strain hardening and multiple cracking behavior. Compared with SFRC, UHPC is advantageous in weight reduction owing to its high strength. In view of the excellent mechanical properties of UHPC, this paper presented an experimental investigation on applying UHPC in the negative moment region.

In this study, the negative flexural behavior of steelUHPC composite beams with different joints was experimentally investigated. The ultimate load, the load-displacement response, and the crack distribution are applied to evaluate the effect of the joint forms on the cracking performance of the composite beams. Finite element analyses were thus also carried out to model the three composite beams. Based on these tests and simulation results and considering the mechanical behavior, as well as the convenience and cost of construction, an applicable joint for the negative moment region and the laying length proportion of UHPC were proposed to enhance the cracking resistance of the concrete slab in the negative moment region for composite beams. Finally, a simplified formula for calculating UHPC crack width was developed based on bond-slip theory.

\section{Experimental Program}

2.1. Test Specimens. Three composite beams, CB-1, CB-2, and CB-3, were tested in this study. Each beam consisted of two simply supported welded steel I-girders with a single span of $1500 \mathrm{~mm}$ and a continuous UHPC slab that was cast on the steel girders. For more enhancement of cracking performance, three different forms of joint at the internal support were designed. The details for the beams, including the span layout, the cross section, and joint forms, are shown in Figure 1. The composite beams were designed to develop full composite action between the steel girder and the UHPC slab through $10 \mathrm{~mm}$ diameter, $40 \mathrm{~mm}$ long shear studs welded to the top flange of the steel girder. In the UHPC slabs, appropriate amounts of $14 \mathrm{~mm}$ diameter longitudinal reinforcements and $10 \mathrm{~mm}$ diameter transverse reinforcements with a nominal yielding strength of $400 \mathrm{MPa}$ (HRB400) were properly spaced. To prevent web distortion, vertical stiffeners are welded to the web of the steel beam at the supports.
Figure 1(b) shows the joint forms of steel girders for the three composite beams. In the CB-1, only the top flanges of the adjacent steel girders were welded together at the joint. CB-2 and CB-3 were similar to CB-1, except that the webs of CB-2 and CB-3 were also partially welded together at the joint.

2.2. Material Properties. The mix design of UHPC in this study is given in Table 1 . The UHPC was reinforced by $13 \mathrm{~mm}$ long, $0.2 \mathrm{~mm}$ diameter hooked-end steel fibres, and the fibre content was $2.5 \%$ by volume of UHPC. Three cubes with side lengths of $100 \mathrm{~mm}$, six prisms with dimensions of $100 \mathrm{~mm} \times 100 \mathrm{~mm} \times 300 \mathrm{~mm}$, and three prisms with dimensions of $100 \mathrm{~mm} \times 100 \mathrm{~mm} \times 400 \mathrm{~mm}$ were prepared for the material property tests of UHPC. The mechanical properties of the steel plates and HRB400 rebar were obtained through coupon tests. Tables 2 and 3 summarize the mechanical properties of these materials.

2.3. Test Setup and Instrumentation. To simulate the negative moment region over the internal support, two springs were applied instead of roller end supports of the composite beams. The beams were tested by applying two concentrated loads at the spring support ends with two hydraulic jacks, as shown in Figure 1. Compared with applying load at the midspan, this loading method can achieve larger rotation angle and negative bending moment at the internal support, which makes it easier to observe the whole process of crack development and yield and failure mode of the slabs. The loading process was controlled by the displacement of the springs, with an increment of $0.5 \mathrm{~mm}$ per stage. The loading was stopped when the displacement of the spring reached $30 \mathrm{~mm}$.

The beams were instrumented for the purpose of measuring applied load, deflections, crack formation, crack development, and sectional strains across the depth. Strain gauges were mounted on the UHPC slab, steel beams, and steel reinforcements for measuring the longitudinal strains in the specimens. The deflections at the support locations in each loading step were measured using four electronic deflection gauges. Moreover, four load cells were placed at the supports to record the load. Figure 2 shows the arrangement of the deflection gauges and strain gauges. In the tests, the crack width and crack development were also detected and recorded in each load step with a digital crack-observation device.

\section{Test Results}

3.1. Test Observations. According to Rafiee [9], cracks with widths less than $0.05 \mathrm{~mm}$ have little effect on the durability of UHPC, and thus a crack width of $0.05 \mathrm{~mm}$ can be defined as the critical width. The load corresponding to the appearance of a $0.05 \mathrm{~mm}$ wide crack can be defined as the critical load, and the stress calculated through the load is referred to as the nominal tensile stress. In this paper, this state is defined as the critical cracking state. 


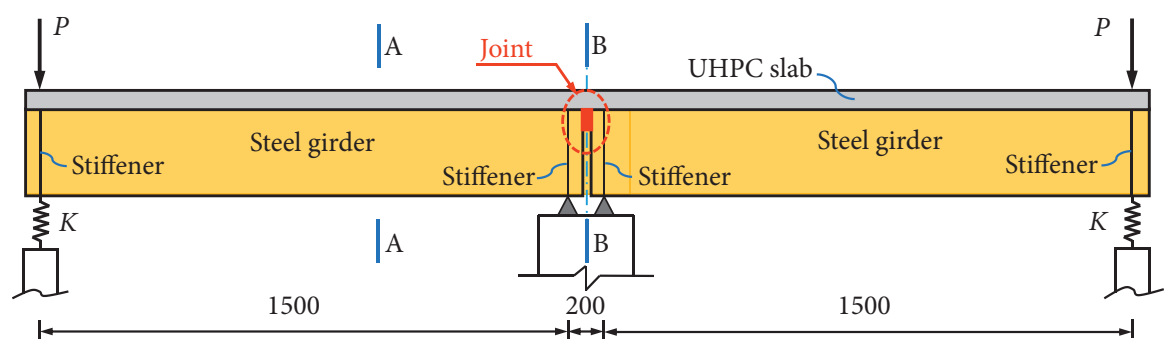

(a)

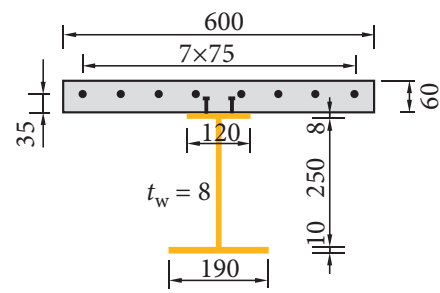

Section A-A

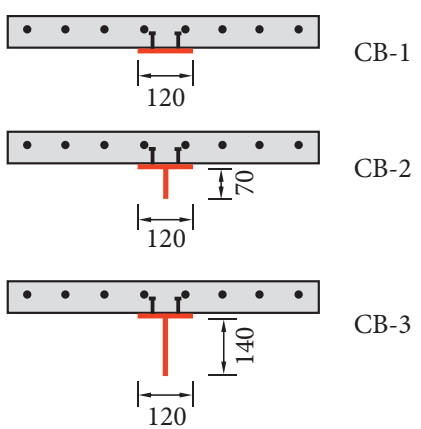

Section B-B

(b)

Figure 1: Details of the beams: (a) longitudinal configuration and (b) Section A-A and joints (units: mm).

TABLE 1: Mix design of UHPC.

\begin{tabular}{lc}
\hline Material & Mass ratio \\
\hline Cement & 1 \\
Silica fume & 0.25 \\
Quartz sand & 1.1 \\
Quartz powder & 0.3 \\
Water reducer & 0.019 \\
Water & 0.2 \\
\hline
\end{tabular}

TABLE 2: Material properties of UHPC (units: MPa).

\begin{tabular}{lccc}
\hline Material & $f_{c u}$ & $f_{t}$ & $E_{c}$ \\
\hline UHPC & 152.3 & 8.2 & 47300 \\
\hline
\end{tabular}

TABLE 3: Material properties of steel and reinforcement.

\begin{tabular}{lccc}
\hline Material & $\begin{array}{c}\text { Thickness or } \\
\text { diameter }(\mathrm{mm})\end{array}$ & $\begin{array}{c}\text { Yield strength } \\
(\mathrm{MPa})\end{array}$ & $\begin{array}{c}\text { Young's } \\
\text { modulus }(\mathrm{MPa})\end{array}$ \\
\hline Steel & $t=8$ & 353.7 & 206000 \\
plate & $t=10$ & 360.1 & 206000 \\
\hline \multirow{2}{*}{ HRB400 } & $d=10$ & 468.6 & 200000 \\
& $d=14$ & 497.4 & 200000 \\
\hline
\end{tabular}

The results of three test beams are summarized in Table 4 , including the load, displacement, crack width, and strain of the steel beam and UHPC under the critical cracking state and the final state. The final state is defined as the state that the spring displacement reached $30 \mathrm{~mm}$ and then the loading was stopped. Taking CB-1 (Figure 3 ) as an example for a detailed description, when the total displacement of the spring increased to $4 \mathrm{~mm}, 2-3$ transverse cracks with widths of $0.05 \mathrm{~mm}$ appeared on the top surface of the UHPC slab at the joint, and the corresponding rotation angle at the internal supports was $0.14^{\circ}$; the tensile strain of the UHPC slab over the joint was $1453 \mu \varepsilon$. As the load increased, the angular displacement at the internal supports continued to increase, and more cracks appeared on the top surface of the UHPC slab. When the spring displacement reached $12 \mathrm{~mm}$, the rotation angle at the internal supports was $0.43^{\circ}$, and the maximum crack width reached $0.31 \mathrm{~mm}$; the cracks extended transversely to the edges of the UHPC slab, becoming wider and mainly distributed at the joint in the negative moment region (section $\mathrm{B}-\mathrm{B}$ in Figure 1). Finally, when the spring displacement reached $30 \mathrm{~mm}$, the rotation angle at the internal supports was $1.07^{\circ}$, the width of the main cracks on the top of the UHPC slab reached $1.03 \mathrm{~mm}$, and the tensile strain was $5750 \mu \varepsilon$; the angular displacement at the internal supports was sufficiently large to stop the loading.

For CB-2 and CB-3, the test process and crack development modes were very similar to those of CB-1. In the final state, the rotation angles at the internal supports of CB2 and CB-3 were both $1.07^{\circ}$, and the tensile strains of the UHPC were $5152 \mu \varepsilon$ and $4813 \mu \varepsilon$, respectively.

However, the stress state of the top flange and web of the steel girder in these two beams differed from that of CB-1 due to the different forms of joints. In the final state, the top flange of CB-1 was in compression at the joint, and the compressive strain was $1453 \mu \varepsilon$. However, the top flanges of CB-2 and CB-3 were in tension at the joint because the webs were also welded, and the tensile strains in the flanges of these beams were $1114 \mu \varepsilon$ and $863 \mu \varepsilon$, respectively, which were still in the elastic state. The bottoms of the welded webs 


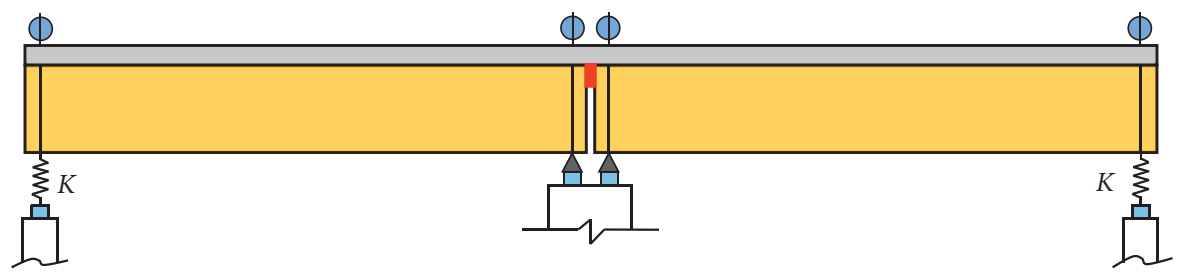

$\varnothing$ - Electronic deflection gauge

$\square$ L Load cell

(a)

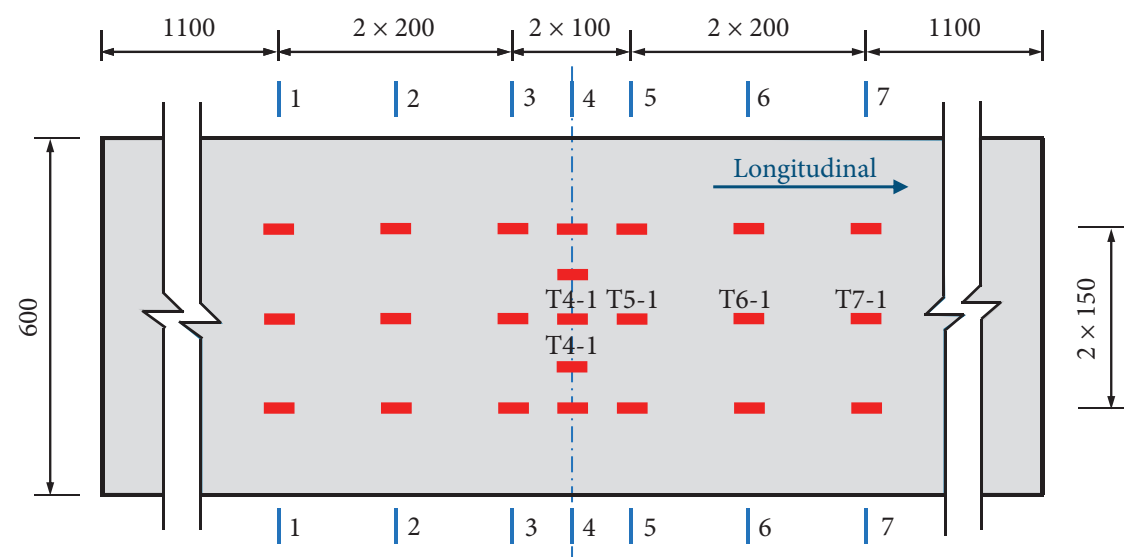

(b)

FIgURE 2: Layout of the test instruments: (a) deflection gauges and (b) strain gauges on the UHPC slab (units: mm).

TABLE 4: Main test results.

\begin{tabular}{lccccccc}
\hline State & $\begin{array}{c}\text { Test } \\
\text { beam }\end{array}$ & $\begin{array}{c}\text { Load } \\
(\mathrm{kN})\end{array}$ & $\begin{array}{c}\text { Displacement } \\
(\mathrm{mm})\end{array}$ & $\begin{array}{c}\text { Rotation } \\
\left(^{\circ}\right)\end{array}$ & $\begin{array}{c}\text { Crack width } \\
(\mathrm{mm})\end{array}$ & $\begin{array}{c}\text { Strain of UHPC top } \\
\text { surface }(\mu \varepsilon)\end{array}$ & $\begin{array}{c}\text { Strain of top flange of } \\
\text { steel girder }(\mu \varepsilon)\end{array}$ \\
\hline \multirow{2}{*}{ Critical cracking } & CB-1 & 9.0 & 4 & 0.14 & 0.05 & 1453 & 269 \\
state & CB-2 & 16.6 & 6.5 & 0.23 & 0.05 & 1516 & 231 \\
& CB-3 & 32.1 & 7 & 0.25 & 0.05 & 1774 & 206 \\
\multirow{3}{*}{ Final state } & CB-1 & 35.3 & 30 & 1.07 & 1.03 & 5750 & 1453 \\
& CB-2 & 42.3 & 30 & 1.07 & 0.92 & 5152 & 1114 \\
& CB-3 & 59.0 & 30 & 1.07 & 0.51 & 4813 & 863 \\
\hline
\end{tabular}

were in compression at the joint. In the final state, local buckling occurred on the welded webs due to their small compressive area, and the maximum compressive strains of webs at the joint were $4264 \mu \varepsilon$ and $3623 \mu \varepsilon$ for CB-2 and CB3 , respectively.

\subsection{Crack Distribution and Rotation-Crack Width} Relationship. The final crack distribution and maximum crack widths in the negative moment region are shown in Figure 4 . The cracks in CB-1 were closely spaced and concentrated between the internal supports, with a maximum width of $1.03 \mathrm{~mm}$. CB-2 exhibited a crack distribution similar to that of CB-1, with a smaller maximum crack width of $0.92 \mathrm{~mm}$. Compared with the other two beams, the cracks in CB-3 had a wider distribution and were more uniformly spaced, with the smallest maximum crack width of $0.51 \mathrm{~mm}$. These results indicate that CB-3 has greater cracking performance with smaller crack width, chiefly because the cross-sectional stiffness of CB-3 was larger than those of CB-1 and CB-2 at the joint.

Figure 5 shows the rotation-crack width relationship of the three beams. When the crack width reached the critical value of $0.05 \mathrm{~mm}$, the angular displacements of CB-1, CB-2, and $\mathrm{CB}-3$ were $0.14^{\circ}, 0.23^{\circ}$, and $0.25^{\circ}$, respectively, and the strains on the top surface of the UHPC slab were $1453 \mu \varepsilon$, $1516 \mu \varepsilon$, and $1774 \mu \varepsilon$, respectively. Apparently, UHPC has a much higher critical cracking strain than conventional concrete, which demonstrates that the adoption of UHPC in the negative moment region can significantly improve the cracking resistance of steel-concrete composite beams. Compared with the other two beams, CB-3 had larger angular displacement and larger tensile strain, demonstrating that CB-3 has greater cracking performance than the other two beams.

In the final state, the crack widths of CB-1, CB-2, and CB-3 were $1.03 \mathrm{~mm}, 0.92 \mathrm{~mm}$, and $0.51 \mathrm{~mm}$, respectively, and the 


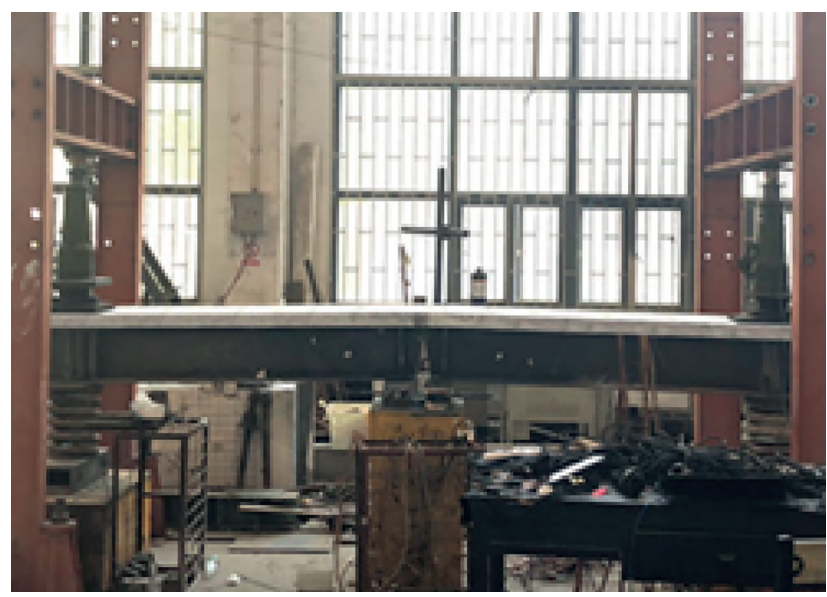

FIgURE 3: Rotation of the composite beam.

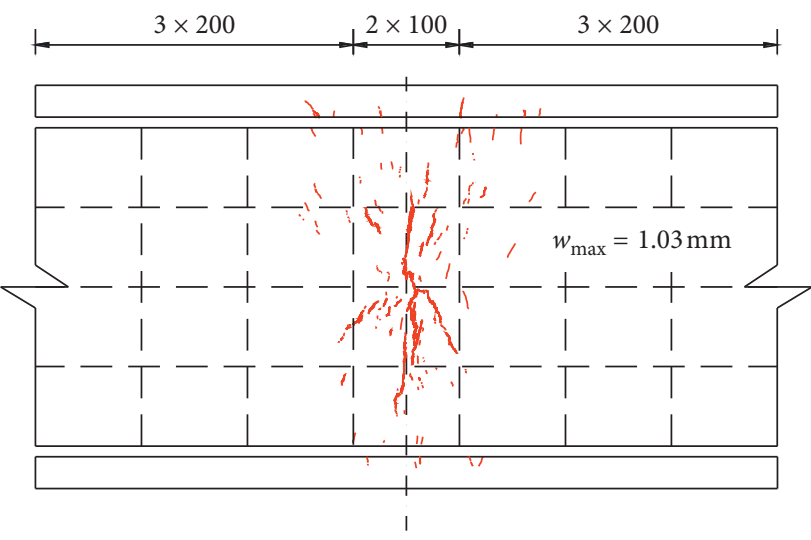

(a)

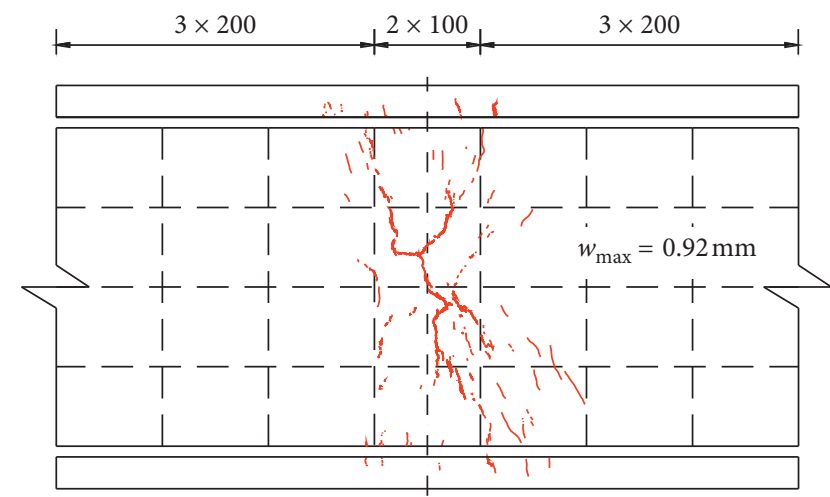

(b)

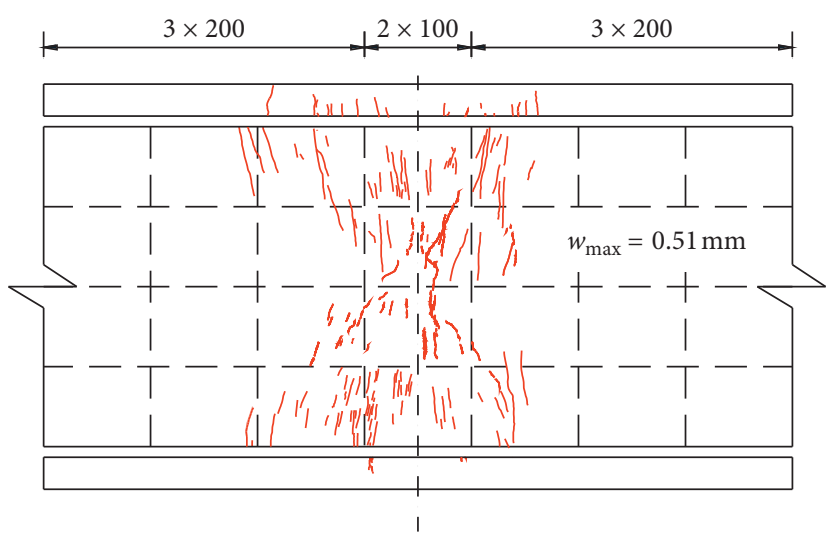

(c)

FIgURE 4: Crack distribution in the UHPC slabs (units: mm): (a) CB-1, (b) CB-2, and (c) CB-3.

strains at the top surface of the UHPC slab were $5750 \mu \varepsilon$, $5152 \mu \varepsilon$, and $4813 \mu \varepsilon$, respectively. These results showed that joint forms have a great influence on the strain and cracking of the slab in the negative moment region. The joint form in CB-3 has greater stiffness and flexural capacity than that in CB-1 and CB-2, and these characteristics can effectively reduce the strain and crack width in the negative moment region. It can be concluded that the stiffness improvement of the joint has positive influences on the cracking behavior and the failure mode of steel-UHPC composite beams. With the increasement of joint stiffness, the cracking strength was improved and the development of cracks was delayed. 


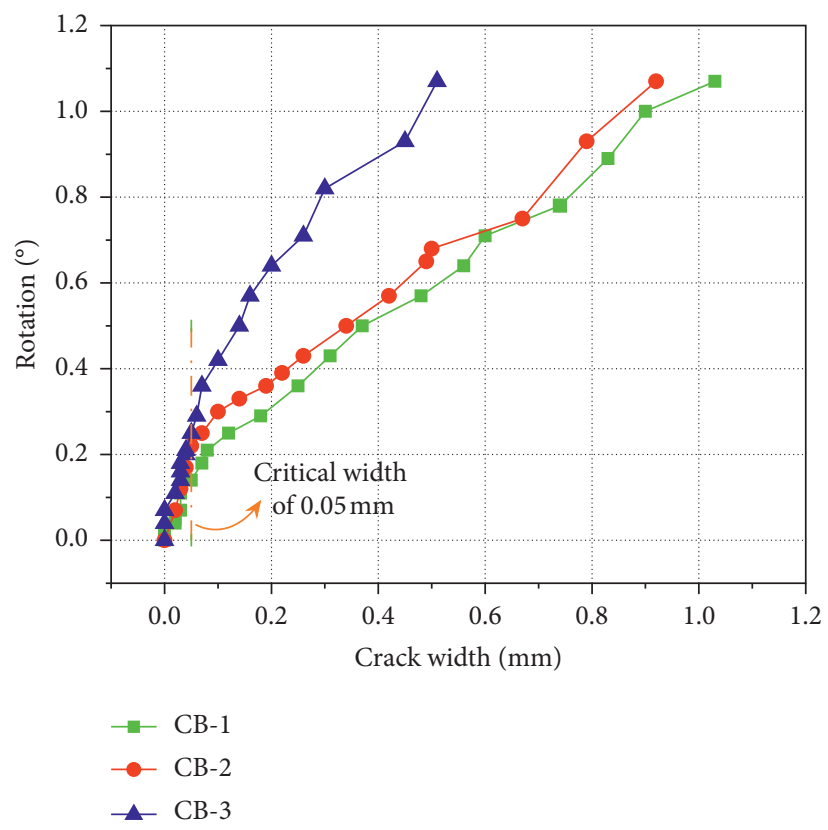

FIGURE 5: Rotation-crack width relationship.

3.3. Load-Spring Displacement Curves. Figure 6 shows the load-spring displacement response of the three beams. For the early stage, before the spring displacement reached $7 \mathrm{~mm}$, the load-spring displacement curve of CB-3 has the highest rate of increase and that of $\mathrm{CB}-1$ has the lowest. The secant slopes of CB-1, CB-2, and CB-3 were 1.29, 2.11, and 4.14 , respectively, corresponding to a load equal to $0.5 \mathrm{P}_{\mathrm{u}}$ (ultimate load); the stiffnesses of CB-2 and CB-3 were approximately $60 \%$ and $220 \%$ greater than that of CB-1, respectively. The moment-rotation curves were similar to the load-spring displacement curves and are shown in Figure 7. For the early stage, before the rotation angle reached $0.25^{\circ}$, the moment-rotation curve of CB-3 has the highest rate of increase and that of CB-1 has the lowest. The results indicate that the overall stiffness of CB-3 is the greatest while CB-2 is the greater and CB-1 is the smallest.

The test results showed that welding the web at the joint contributed to the load-carrying capacity of the composite beam and that the height of the welded web had a great influence on the load-carrying capacity. The load-carrying capacities of CB-2 and CB-3 were approximately $40 \%$ and $140 \%$ greater than that of $\mathrm{CB}-1$, respectively.

3.4. UHPC Rotation-Strain Relationship. The rotation-longitudinal strain curves of critical measuring points on the top surface of the UHPC slab in the negative moment region are shown in Figure 8. The strain of the UHPC slab over the joint increased with increasing angular displacement, and the rotation-strain curves were approximately linear. The results of three test beams show that the tensile strain distribution along the length of the slab was uneven. The strains of the slab were largest at the joint (measuring point T4-1) and gradually decreased away from the joint. When the rotation angles of the beams were relatively small,

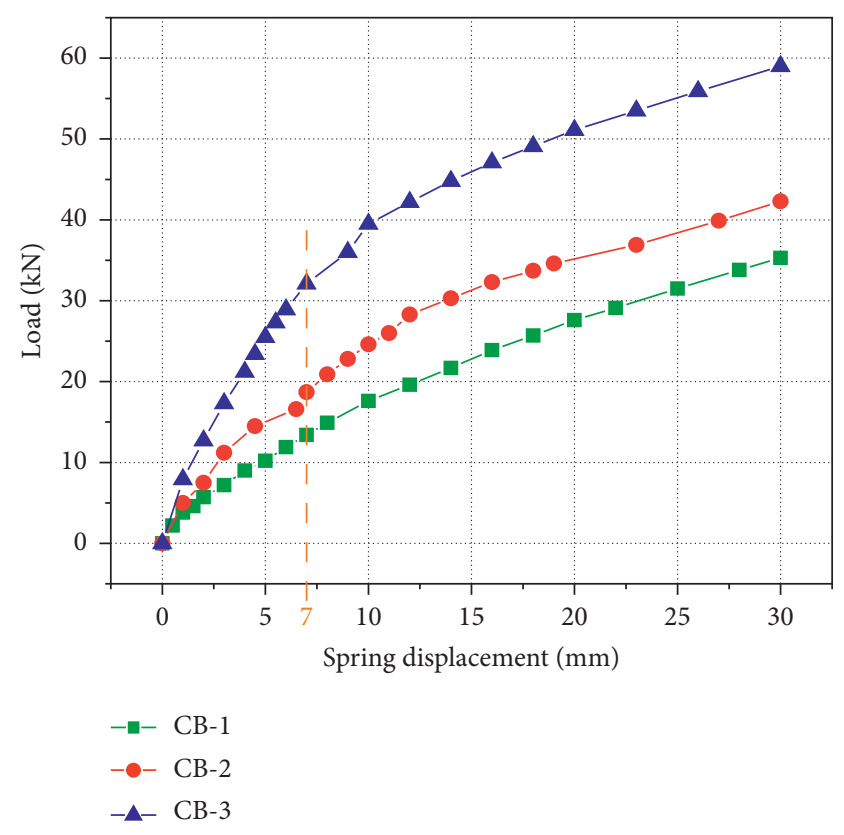

Figure 6: Load-spring displacement curves.

corresponding to critical cracking, the tensile strains outside the range of $500 \mathrm{~mm}$ from the joint were less than $500 \mu \varepsilon$, which greatly reduced the requirements of the cracking performance. Under the same spring displacement, for a single critical point (T4-1), the strain of CB-1 was the highest and that of CB-3 was the lowest, indicating that the joint of CB-1 led to better cracking performance.

Under the ultimate state, the tensile strains on the UHPC top surface of the three beams exceeded $4500 \mu \varepsilon$, thereby fully utilizing the tensile performance of UHPC. 


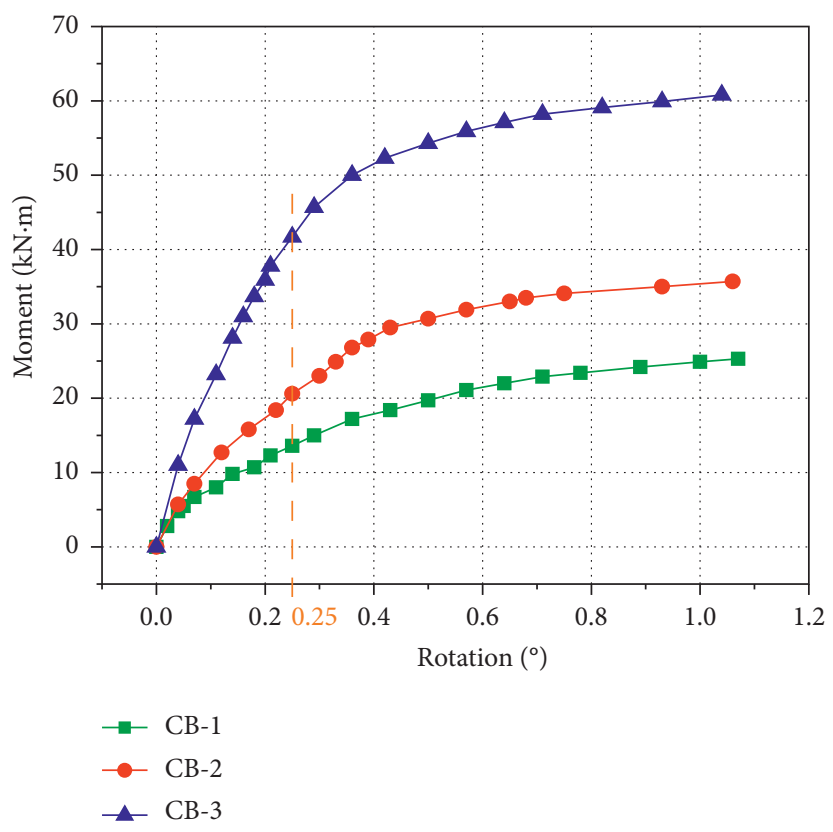

FIGURE 7: Moment-rotation curves.

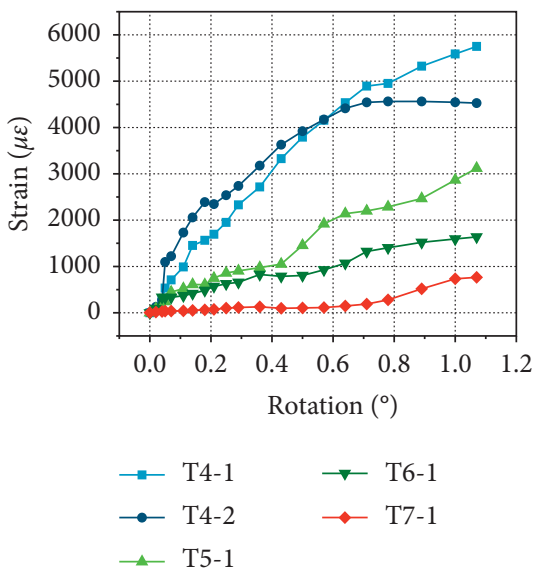

(a)

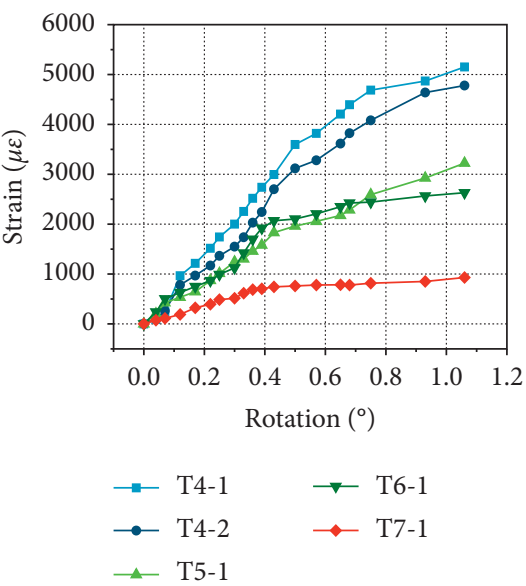

(b)

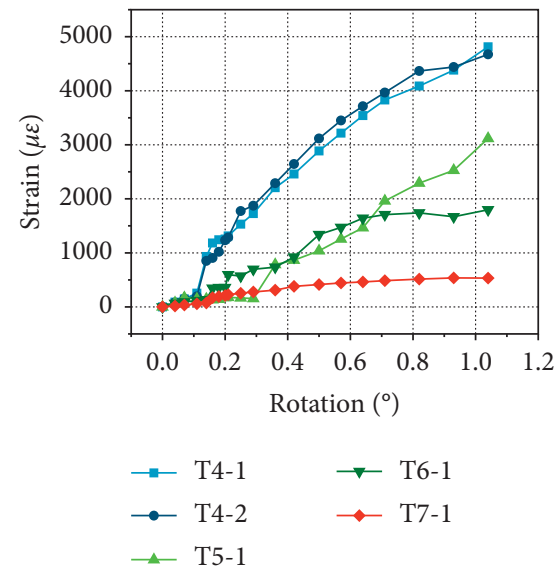

(c)

FIgURE 8: Rotation-strain relationships of UHPC slabs: (a) CB-1, (b) CB-2, and (c) CB-3.

\section{Finite Element Analysis}

To verify the reliability of the test results, nonlinear analyses were carried out to simulate the test process and comprehensively analyse the test beams, which laid the foundation for further structural analysis.

4.1. Modelling. The nonlinear finite element models were established using the commercial software program ABAQUS, as shown in Figure 9. The steel girder, UHPC, bearing, and shear studs were modelled using eight-node brick elements (C3D8R); the steel reinforcements, which were connected with the UHPC slab by an embedded restraint, were modelled using a two-node linear 3D truss element (T3D2). The shear stud was divided into two parts; the upper

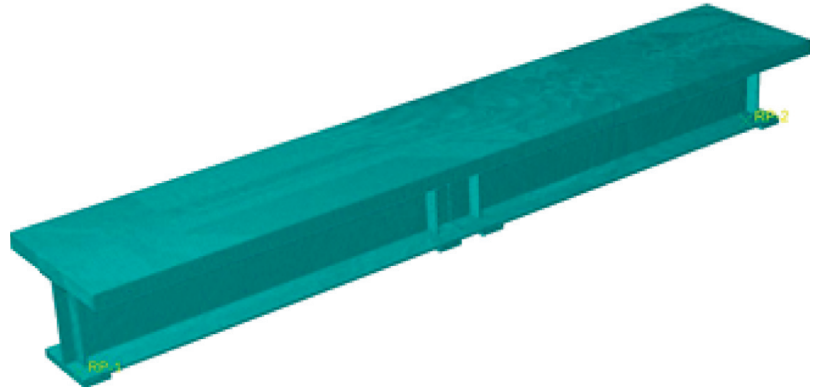

Figure 9: Model of the composite beam.

part of which was connected with the UHPC slab and the lower part of which was connected with the top flange of the steel beam by an embedded restraint. Surface-to-surface 
contact was used to define the concrete-steel interaction; the tangential direction of the interface adopted a penalty function, and the friction coefficient was 0.3 [10]; the normal direction of the interface adopted hard contact. The interaction between the support block and the steel beam adopted a tie constraint. In addition, the influence of mesh size on the accuracy of the numerical simulation has been investigated with different mesh sizes. After comparison of the numerical results, the mesh size of $1 \mathrm{~cm}$ was used for UHPC slab and steel beam, the mesh size of $5 \mathrm{~mm}$ was used for steel reinforcements, and the mesh size of $2 \mathrm{~mm}$ were used for shear studs. The loads on the FE model were applied using displacement control by two reference points.

4.2. Stress-Strain Relationship. The compressive stress-strain relationship of UHPC (Figure 10) proposed by Shan [11] was used herein, which is given as follows:

$$
\frac{\sigma}{f_{c}}= \begin{cases}a x+(6-5 a) x^{5}+(4 a-5) x^{6}, & 0 \leq x<1, \\ \frac{x}{b(x-1)^{2}+x}, & x \geq 1,\end{cases}
$$

where the compressive strength $f_{c}=152.3 \mathrm{MPa} ; x=\varepsilon / \varepsilon_{c 0}$, in which $\varepsilon_{c 0}$ is the strain corresponding to the peak and $\varepsilon_{0}=3500 \mu \varepsilon ; a$ is the ratio of the initial tangent modulus $\left(E_{c}=47.3 \mathrm{GPa}\right)$ to the peak secant modulus $\left(E_{\mathrm{sec}}=f_{c} / \varepsilon_{0}\right)$; and $b$ is a test fitting parameter equal to 2.41 .

The tensile stress-strain relationship of UHPC (Figure 10) comprises a two-stage tensile constitutive model [12], and the descending constitutive model [13] is given as follows:

$$
\sigma_{t}= \begin{cases}E_{c} \varepsilon_{t}, & 0 \leq \varepsilon_{t} \leq \varepsilon_{t 0}, \\ f_{t}, & \varepsilon_{t 0}<\varepsilon_{t} \leq \varepsilon_{t p}, \\ \frac{f_{t}}{\left(1+\left(\varepsilon_{t}-\varepsilon_{t p}\right) l_{c} / w_{p}\right)^{p}}, & \varepsilon_{t p}<\varepsilon_{t},\end{cases}
$$

where the tensile stress $f_{t}=8.2 \mathrm{MPa}, \varepsilon_{t p}=2000 \mu \varepsilon$, $w_{p}=0.7 \mathrm{~mm}, l_{c}=40 \mathrm{~mm}$, and $p=1.0$.

The constitutive relationships of the steel beam and reinforcement applied an ideal elastoplastic model. The yield strength was obtained through testing, as shown in Table 3.

Three constitutive models are available in ABAQUS for concrete: the smeared cracking model, the brittle cracking model, and the damaged plasticity model. Since the strain softening of concrete under tensile-compressive biaxial stress was considered, the damage plasticity model can better simulate the mechanical deformation behavior of concrete beams than the other models, and the concrete tensile plasticity was simulated through strain hardening and strain softening of the descending branch.

The damaged plasticity model of UHPC is composed of elasticity and plasticity. Elastic parameters include elastic modulus and Poisson's ratio and were obtained through material tests to be $E=47.3 \mathrm{GPa}$ and $v=0.2$, respectively.
The plastic parameters were set according to the ABAQUS user manual [14], as shown in Table 5. The plastic-damage constitutive relationship of UHPC was determined by the energy equivalence principle based on the constitutive stress-strain relationship. The damage factor of tensile and compressive UHPC could be calculated using equation (3) with the stress-strain response obtained from equations (1) and (2) [15]:

$$
D=1-\sqrt{\frac{\sigma}{E \varepsilon}}
$$

4.3. Finite Element Analysis Results. Three moment-rotation curves obtained from the nonlinear finite element analysis are compared with the test results in Figure 11. The moment of the test beams was derived by the values obtained from load cells. The characteristic points of numerical analysis for CB-1, CB-2, and CB-3 are basically consistent with those in the test results, including the cracking point and the yield point. Therefore, the comparison shows that the three finite element models can accurately simulate the whole bending process of these steel-UHPC composite beams.

The damaged plasticity model in ABAQUS cannot simulate the cracking of UHPC; however, the cracks can be identified through the principal tensile strain contour plots of UHPC, as shown in Figure 12. Comparing these plots with the measured crack distribution, it is found that the strain contour plot calculated by the model is similar to the crack distribution from the test.

\section{Cracking Performance of UHPC}

Based on the mechanical characteristics of a bridge deck in the negative moment region, one of the following principles could be chosen when designing the slab for the sake of longterm durability: (1) tensile stress is prohibited, (2) critical cracks are prohibited, and (3) crack width is limited. The first principle is rarely used due to the strict requirements for slab stress, which can only be realized through prestressing tendons and is inconvenient. For the second principle, to control critical cracks in a UHPC slab, the maximum tensile stress of the UHPC slab should be controlled to be less than the nominal tensile stress of the UHPC. This paper focuses on the cracking behavior of UHPC in the negative moment region, mainly based on the second design principle.

The second principle is discussed from the following three aspects: (1) the nominal tensile stress of the test beams, (2) the influence of shrinkage on the UHPC cracking performance, and (3) the calculation of the crack width. The nominal tensile stress can be calculated through the test results, as shown in a later section. The shrinkage of UHPC is larger than that of normal concrete due to the low water-tocementitious material ratio, which has a notable effect on the cracking performance of UHPC; therefore, the influence of shrinkage on UHPC cracking performance was studied. In addition, to control critical cracks in the slab, the crack width should be calculated under the given load; thus, a simple 


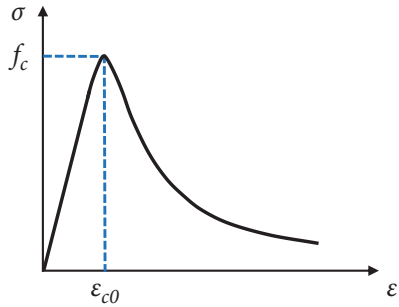

(a)

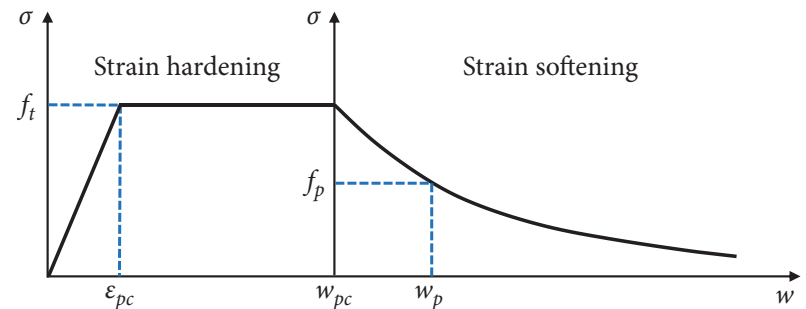

(b)

Figure 10: Stress-strain model for UHPC: (a) compression and (b) tension.

TABLe 5: Parameters for the damaged plasticity model of UHPC.

\begin{tabular}{lcccc}
\hline Expansion angle & Eccentricity & Strength ratio $f$ & $K_{c}$ & \\
\hline $30^{\circ}$ & 0.1 & 1.16 & $2 / 3$ & Viscosity \\
\hline
\end{tabular}

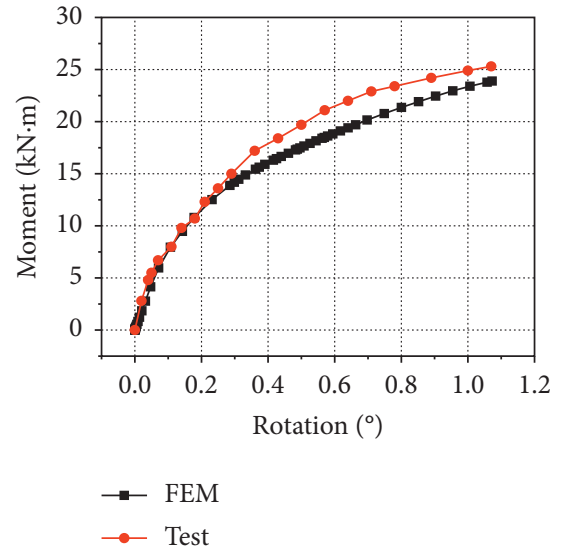

(a)

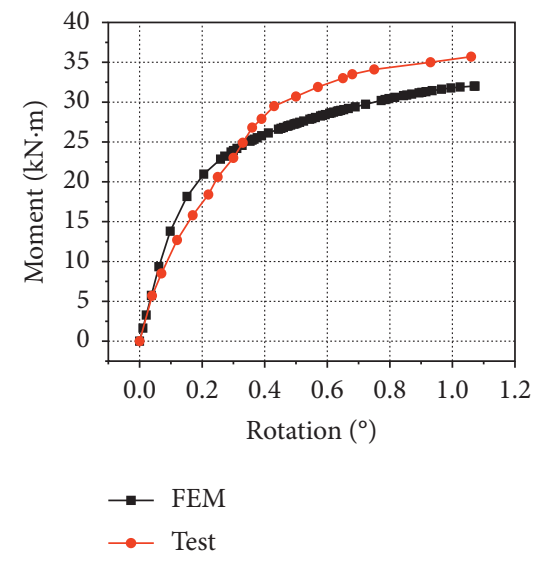

(b)

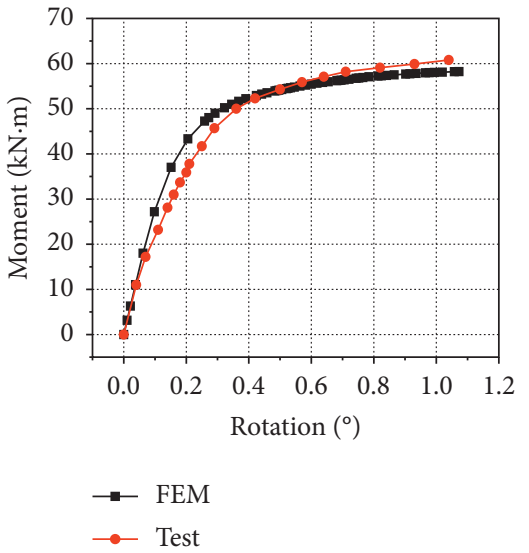

(c)

Figure 11: Moment-rotation curves: (a) CB-1, (b) CB-2, and (c) CB-3.

formula for calculating crack width was proposed based on bond-slip theory.

5.1. UHPC Nominal Tensile Stress. The nominal tensile stress $f_{c r}$ of a steel-UHPC composite beam was derived as follows:

$$
f_{c r}=\frac{M_{c r}}{\alpha_{E} I} \times h_{t}
$$

where $M_{c r}$ is the cracking moment, $\alpha_{E}$ is the ratio of elasticity modulus of steel and concrete, $I$ is the moment of inertia of the composite section, and $h_{t}$ is the distance from the section centroid to the UHPC surface. The cracking moment $M_{c r}$ was calculated from the critical cracking load $F_{c r}$ obtained through testing. The slip between the steel plate and the UHPC was not considered. Table 6 shows the calculation results.

Note that the nominal tensile stress of the three steelUHPC composite beams under the negative moment is greater than $23 \mathrm{MPa}$, which is much higher than the tensile design strength of conventional concrete. Apparently, the application of UHPC can greatly enhance the cracking load and inhibit the development of cracks in the negative moment region, which may effectively solve the cracking problem of steel-concrete composite beams in the negative moment region.

5.2. Shrinkage of UHPC. The total shrinkage of UHPC is higher than that of normal concrete or high-performance concrete due to the ultra-low water-to-cementitious material ratio in UHPC. UHPC shrinkage mainly includes drying and autogenous shrinkage. Drying shrinkage is caused by the surface moisture loss in UHPC, and autogenous shrinkage is the consequence of volumetric contraction due to the internal consumption of water during cement hydration.

Shrinkage is caused by internal factors and external factors. The internal factors affecting UHPC shrinkage are those related to its constituents (i.e., aggregates and cements) as follows: the water-cementitious material ratio, the mix design, admixtures, specimen size, and curing conditions. 


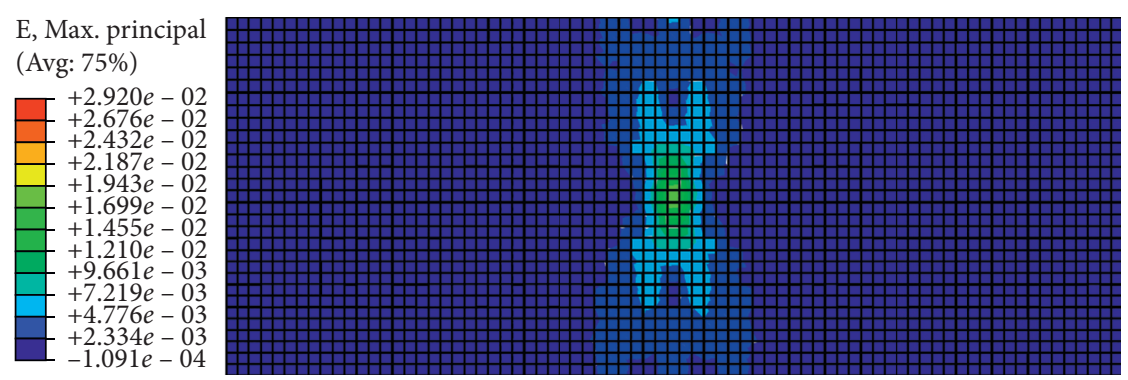

(a)

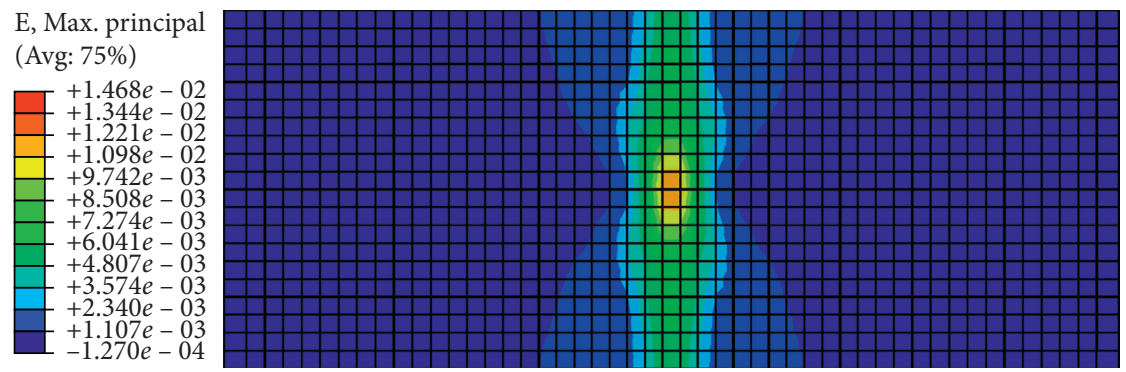

(b)

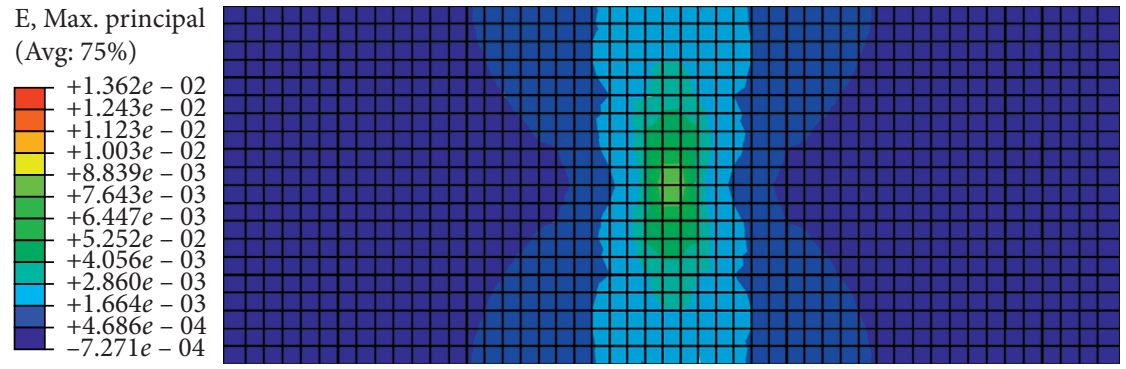

(c)

Figure 12: Principal tensile strain contour plots of UHPC in ultimate states: (a) CB-1, (b) CB-2, and (c) CB-3.

TABle 6: Nominal tensile stress of the model beams.

\begin{tabular}{lcc}
\hline Beam & Cracking strain $(\mu \varepsilon)$ & $\begin{array}{c}\text { UHPC nominal tensile } \\
\text { stress } f_{c r}(\mathrm{MPa})\end{array}$ \\
\hline CB-1 & 1453 & 23.2 \\
CB-2 & 1516 & 25.3 \\
CB-3 & 1774 & 23.9 \\
\hline
\end{tabular}

The external factors include ambient conditions, humidity, and restraints. To reduce the effect of shrinkage on UHPC cracking performance, steam treatment is generally used in the laboratory (the test beams in this study also adopted steam treatment), which can accelerate the shrinkage to such an extent that the entirety of the shrinkage occurs during a 2day treatment, and the UHPC is then stabilized against further shrinkage [16]. However, steam curing is difficult to achieve at construction sites due to the limitation of UHPC construction conditions. This paper considers the effects of the curing conditions, constraints, steel fibres, and admixtures on the shrinkage and the effect of UHPC shrinkage on the cracking performance of the composite beams.

(1) Curing conditions have a crucial impact on UHPC shrinkage. The shrinkage of UHPC is approximately zero after steam curing, which is beneficial to the structure but difficult to implement at construction sites. Greybeal concluded that when no steam curing is conducted, UHPC tends to exhibit approximately $800 \mu \varepsilon$ of shrinkage, as measured 1 year after casting [16]. According to the French specification [17], in an environment with an average relative humidity of $50 \sim 70 \%$, the autogenous shrinkage and drying shrinkage are $500 \mu \varepsilon$ and $150 \mu \varepsilon$, respectively, such that the total shrinkage reaches a total of $700 \mu \varepsilon$. The Japanese specification [18] stipulates that the total shrinkage of UHPC with no steaming should be $550 \mu \varepsilon$. The Swiss specification [19] and the Federal Highway Administration (FHWA) study report [20] suggest that the total shrinkage of UHPC is 600-800 $\mu \varepsilon$ without steam curing. Therefore, for UHPC under normal moist curing without steaming, the autogenous shrinkage and drying shrinkage are approximately $550 \mu \varepsilon$ and $150 \mu \varepsilon$, respectively, for a total of approximately $700 \mu \varepsilon$.

(2) Steel bars have a restraint on UHPC shrinkage. Huang and $\mathrm{Hu}$ investigated the shrinkage characteristics of UHPC with different reinforcement ratios 
under steam curing and concluded that the shrinkage value of unreinforced UHPC is approximately 2.5 times that of UHPC with a reinforcement ratio of $4.52 \%$ [21]. Since steam curing only accelerates autogenous shrinkage but has little effect on the overall shrinkage value, a conclusion is drawn that steel bars can significantly constrain the UHPC shrinkage under steam curing or normal moist curing, and the autogenous shrinkage of UHPC with a reinforcement ratio of $5 \%$ can be reduced by more than $50 \%$.

(3) The presence of steel fibres is able to decrease the shrinkage. Wu et al. concluded that drying shrinkage can be reduced by more than $20 \%$ by adding a steel fibre content of $2 \%$ by volume [22].

In summary, the shrinkage strain in UHPC without steam treatment is approximately $700 \mu \varepsilon$. Through the addition of a steel fibre content of $2 \%$ by volume, the shrinkage strain of UHPC can be reduced to less than $400 \mu \varepsilon$. An expansive admixture and a shrinkage reducing agent could also be used during the setting of UHPC.

The test results of the three specimens show that in the negative moment region, the critical cracking strain of steelUHPC is greater than $1450 \mu \varepsilon$ under steam curing conditions. However, the shrinkage strain should be taken into account if there is no steam curing, the value of which is less than $400 \mu \varepsilon$. Hence, if there is no steam curing, the cracking strain in the tests will be greater than $1050 \mu \varepsilon$, and the corresponding cracking nominal tensile stress is greater than $18 \sim 20 \mathrm{MPa}$, which can meet the engineering requirements.

5.3. Calculation of UHPC Crack Width. Based on the classical theory of cracks and considering the contribution of the tensioned UHPC between the cracks, the crack width at the most tensioned reinforcement $w_{s}$ is given by the following expression in the French standard [17]:

$$
w_{s}=s_{r, \max , f}\left(\varepsilon_{s m, f}-\varepsilon_{c m, f}\right),
$$

where $s_{r, \max , f}$ is the maximum cracking spacing, $\varepsilon_{s m, f}$ is the average strain in the reinforcement, $\varepsilon_{c m, f}$ is the average strain in the UHPC between cracks, and $\left(\varepsilon_{s m, f}-\varepsilon_{c m, f}\right)$ is calculated with the following expression:

$$
\varepsilon_{s m, f}-\varepsilon_{c m, f}=\frac{\sigma_{s}}{E_{s}}-\frac{f_{c t f m}}{E_{c m}}-\frac{k_{t}\left(f_{c t m, e l}-f_{c t f m}\right)\left(\left(1 / \rho_{\text {eff }}\right)+\left(E_{s} / E_{c m}\right)\right)}{E_{s}},
$$

where $\sigma_{s}$ is the stress in the tensioned reinforcing steel, $\rho_{\text {eff }}$ is the effective reinforcement ratio, $A_{c, \text { eff }}$ is the effective crosssectional area of UHPC around the tensioned reinforcement, and $k_{t}$ is a factor dependent on the duration of the load or its repetition.

The maximum spacing between cracks is calculated from the following expressions:

$$
\begin{aligned}
s_{r, \max , f} & =2.55\left(l_{0}+l_{t}\right), \\
l_{0} & =\frac{1.33 c}{\delta}, \\
l_{t r} & =\left[0.3 k_{2} \frac{1-\left(f_{c t f m} / f_{c t m, e l}\right)}{\delta \eta}\right] \frac{\phi}{\rho_{\mathrm{eff}}} \geq \frac{l_{f}}{2}, \\
\delta & =1+0.5\left(\frac{f_{c t f, m}}{f_{c t m, e l}}\right),
\end{aligned}
$$

where $l_{0}$ is the concrete coating thickness, $l_{t r}$ is the load transmission length, $c$ is the concrete coating for the reinforcement, $\phi$ is the diameter of the reinforcement, $\eta$ is a bond factor (equal to 2.25 for a steel reinforcement), $\delta$ is a factor that expresses the improvement contributed by the fibres in the behavior of the concrete cover area and to the bonding of the reinforcement, and $k_{2}$ is a factor that accounts for the distribution of strain in the cracked section.

Note that the above formula of the strain difference between reinforcing bars and concrete is complicated and has many parameters. To simplify the calculation process, the classical bond-slip theory is used to simplify this formula.

The tests show that when a single crack reached the critical width of $0.05 \mathrm{~mm}$, the surrounding UHPC was uncracked. In this phase of critical crack formation, a strain difference existed only along the load transmission length of the reinforcing bars and concrete [23], and the strain and stress of the reinforcing bars and UHPC can be assumed to be the same as those of the original section except for the transmission length $l_{t r}$. Therefore, for the uncracked section, the reinforcing bars and concrete have the same strain $\left(\varepsilon_{s e}=\varepsilon_{c t}\right)$. Figure 13 shows the strain distribution of the tensioned members. The stress difference in the steel bars along the load transmission length is balanced by the bond force:

$$
\pi d_{s} l_{t r} \tau_{b m}=A_{r}\left(\sigma_{s r}-\sigma_{s e}\right),
$$

where $d_{s}$ is the diameter of the rebar, $\tau_{b m}$ is the bond stress averaged over the transmission length, $A_{r}$ is the crosssectional area of the rebar, $\sigma_{s r}$ is the rebar stress in the cracking cross section, and $\sigma_{s e}$ is the rebar stress on both sides of the crack.

$$
\sigma_{s e}=E_{s} \varepsilon_{c t}=\alpha_{E} \sigma_{c t},
$$

where $\alpha_{E}=E_{s} / E_{c}$, in which $E_{s}$ and $E_{c}$ are the elastic moduli of steel and concrete, respectively.

The load transmission length is derived from equations (11) and (12) as follows:

$$
l_{t r}=\frac{\left(\sigma_{s r}-\alpha_{E} \cdot \sigma_{c t}\right) d_{s}}{4 \tau_{b m}} .
$$

The strain difference between both ends of the rebar over the transmission length is $\Delta \varepsilon_{s r}=\varepsilon_{s r}-\varepsilon_{s e}$. The average rebar and UHPC strains are derived as follows: 


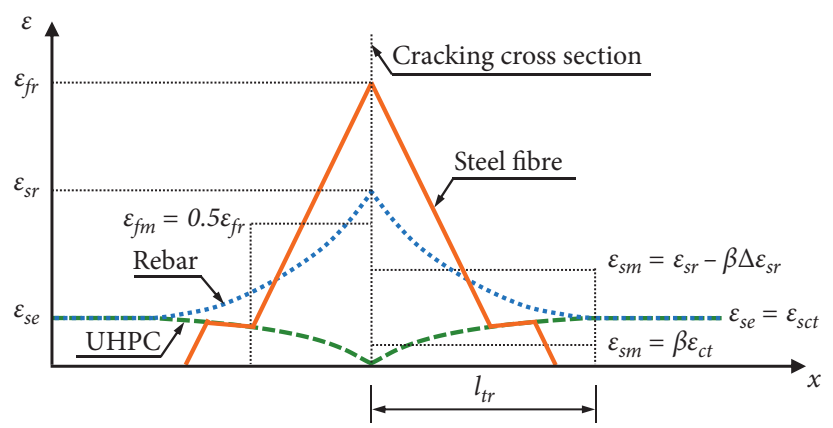

FIGURE 13: Strain distribution in the UHPC, steel fibre, and rebar.

$$
\begin{aligned}
& \varepsilon_{s m}=\varepsilon_{s r}-\beta \Delta \varepsilon_{s r}=(1-\beta) \varepsilon_{s r}+\beta \varepsilon_{s e}, \\
& \varepsilon_{c m}=\beta \cdot \varepsilon_{c t}=\beta \cdot \varepsilon_{s e} .
\end{aligned}
$$

The strain difference between rebars and concrete is calculated as follows:

$$
\varepsilon_{s m}-\varepsilon_{c m}=(1-\beta) \cdot \varepsilon_{s r},
$$

where $\beta$ is the average strain distribution factor, which is defined as $\beta \cdot \Delta \varepsilon_{s r}=\left(1 / l_{t r}\right) \int_{0}^{l_{t r}} \varepsilon_{s}(x) \mathrm{d} x$ and is suggested to be $2 / \pi[24]$.

The calculation for crack width at the most tensioned reinforcement $w_{s}$ is simplified as follows:

$$
w_{s}=2.55\left(l_{0}+l_{t}\right)(1-\beta) \frac{\sigma_{s r}}{E_{s}}
$$

Since the UHPC slab and the steel girder are considered as a composite beam in the simplified calculation, it is assumed that the UHPC slab has the same curvature as the steel girder, and the crack width $w_{t}$ on the surface of the UHPC slab can be derived from the crack width $w_{s}$ at the location of the rebar:

$$
w_{t}=w_{s} \cdot \frac{1}{\gamma_{s}}=w_{s} \cdot \frac{h_{1}}{h_{1}-a_{s t}},
$$

where $\gamma_{s}$ is the lever arm coefficient of the reinforcing bar, which describes the capacity contribution of rebar and the effect on inhibiting cracks; $h_{1}$ is the height of the tensioned part of the cross section; and $a_{s t}$ is the distance from the centroid of the rebar to the top surface of the UHPC.

The critical crack width on the top surface of the UHPC slab for the three test beams under the negative bending moment is calculated based on the modified crack formula (equations (17) and (18)), and then the calculated results are compared with the test results, as shown in Table 7 .

The calculated values of the critical crack width for each test beam are in good agreement with the test results, and the calculated values are relatively conservative, which can satisfy the requirements for engineering calculations.

\section{Steel-UHPC Composite Beam Joint Forms}

The test and analysis results above verified the feasibility of applying UHPC to steel-concrete composite beams in the negative moment region. Considering the cracking behavior, load-carrying capacity, web yield strength, and convenient construction, the applicability of different joint forms was evaluated.

The nominal tensile stresses of the three test beams are all above $23 \mathrm{MPa}$ and close to each other. The load-carrying capacity of CB-3 is higher than those of the other two. Considering that the web stiffness of the joints is small in CB-2 and CB-3, which are prone to web distortion, and the joint of CB-1 is easier to construct than those of CB-2 and $\mathrm{CB}-3$, the joint form in $\mathrm{CB}-1$ is more applicable to construction.

At construction sites, the top flange of the steel beam can be welded or bolted at the joint, as shown in Figure 14(a). Compared with a welded connection, a bolted connection is more convenient to construct and is of higher quality. Moreover, if the joint form of CB-3 is chosen to be used from the perspective of load-carrying capacity, the webs under compression should be stiffened to avoid local buckling, as shown in Figure 14(b).

\section{Longitudinal Laying Length of UHPC}

At present, UHPC materials are much more expensive and more complicated to construct than normal concrete. Therefore, the amount of UHPC should be minimized to meet the economic requirements under the premise of meeting the structural mechanical requirements. The longitudinal laying length of UHPC for the steel-UHPC composite beam is determined herein.

A two-span steel-concrete composite bridge is taken as an example, which is simply supported with a continuous link slab and has a clear span of $30 \mathrm{~m}$. The width of a single composite girder is $16.8 \mathrm{~m}$. Figure 15 shows the longitudinal and cross-sectional configurations.

A finite element model was established to determine the maximum tensile stress of the top surface of the UHPC slab in the negative moment region, the value of which is 17.0 MPa. From the perspective of cracking behavior, all three test beams can satisfy the demands of principle (2), which stipulates that the tensile stress is less than the normal stress given in 4.1 .

Figure 16 shows the stress distribution in the top surface of the deck slab along the bridge. Apparently, UHPC can be laid at the place where the tensile stress in the top surface of 
TABLE 7: Calculation of the critical crack width for the test beams.

\begin{tabular}{lcccc}
\hline Beam & Rebar stress $(\mathrm{MPa})$ & Calculation result (1) $(\mathrm{mm})$ & Test result (2) $(\mathrm{mm})$ & (1) - (2) $) /(2)(\%)$ \\
\hline CB-1 & 134.51 & 0.0571 & 0.05 & 14.2 \\
CB-2 & 151.39 & 0.0548 & 0.05 & 9.6 \\
CB-3 & 193.57 & 0.0512 & 0.05 & 2.4 \\
\hline
\end{tabular}

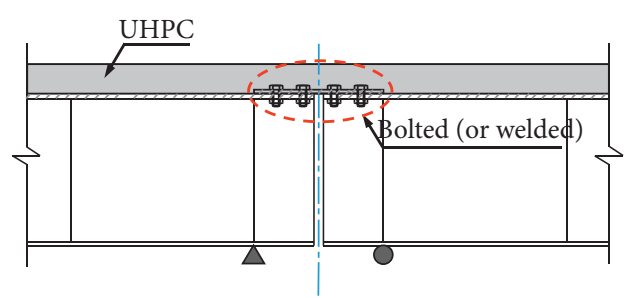

(a)

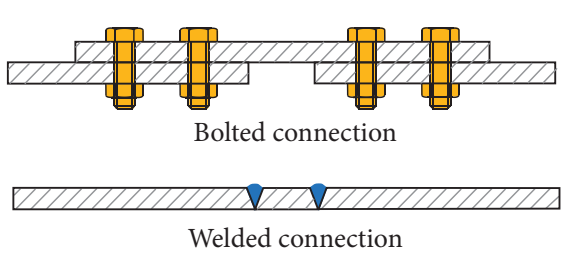

Welded connection

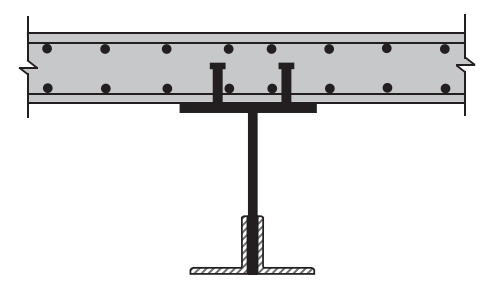

(b)

FIGURE 14: Joint form in the construction site: (a) bolted connection and welded connection and (b) web stiffener for CB-3.

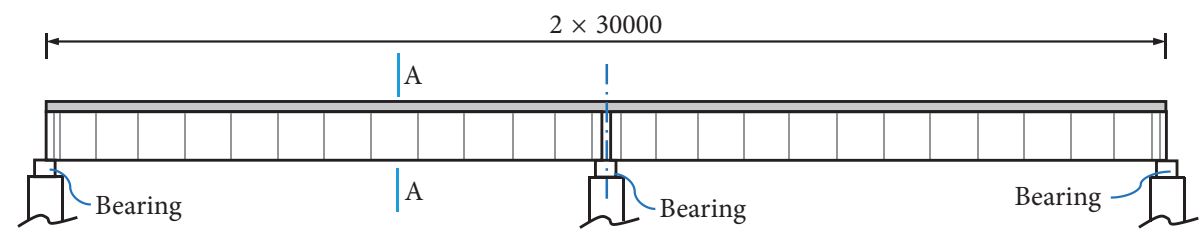

(a)

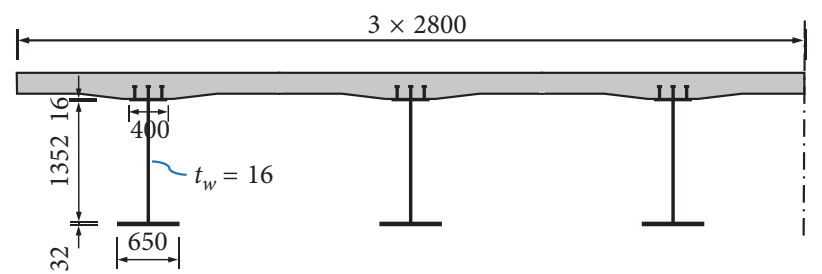

(b)

Figure 15: Details of the steel-concrete composite bridge: (a) span layout and (b) cross section (units: mm).

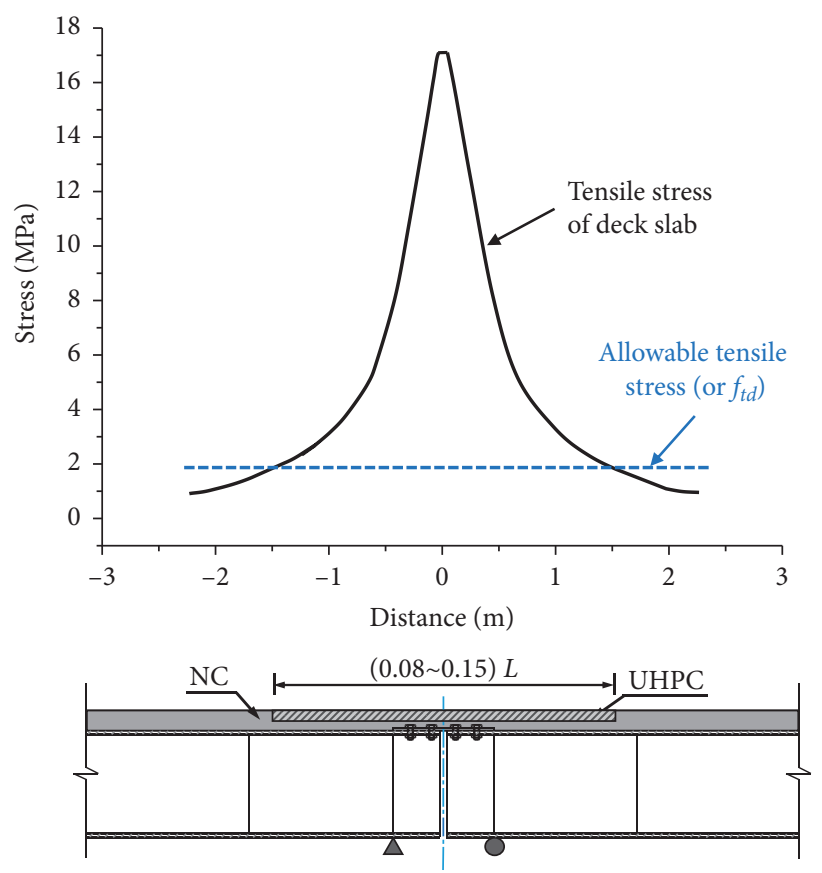

FIGURE 16: Longitudinal laying length of UHPC. 
the deck slab exceeds the allowable tensile stress or, $f_{t d}$, the design tensile strength of deck concrete. Normal concrete can be used in other parts. In the range of approximately $3 \mathrm{~m}$ in the negative moment region, the tensile stress is larger than the tensile strength of normal concrete. Hence, the recommended laying length of UHPC is $3 \mathrm{~m}(0.1 \mathrm{~L})$, which greatly reduces the amount of UHPC under the premise of meeting the structural mechanical requirements.

\section{Conclusion}

This paper presented a method for applying UHPC instead of conventional concrete and new forms of joints in the negative moment region to solve the slab cracking problem of composite beams. Three composite beams were tested, and FE models were analysed to study the mechanical behavior of steel-UHPC composite beams under a negative bending moment. The following conclusions were drawn:

(1) The spring loading method can be applied to simulate the angular displacement and mechanical behavior of the structure in the negative moment region.

(2) The cracking strength of UHPC in composite beams under a negative bending moment is greater than $20 \mathrm{MPa}$, which is much higher than that of steelconcrete composite beams. This finding demonstrates that UHPC can increase the cracking load of composite beams subjected to a negative bending moment; moreover, the cracks in the UHPC are closely spaced, and the development of cracks is greatly inhibited. Thus, the cracking performance of composite beams in the negative moment region greatly improved through the use of UHPC. Then, a simple formula for calculating the crack width is proposed.

(3) The joint form of welding or bolting the top flange of adjacent steel girders in the negative moment region can satisfy the functional requirements and facilitate on-site construction. Since steam curing of UHPC is difficult to achieve on-site, it is recommended to use normal moist curing. The shrinkage strain of UHPC can be reduced by adding steel fibres, introducing expansive agents to the concrete mix, and increasing the reinforcement ratio. Considering the economy of engineering applications, the suggested laying length of UHPC in the negative moment region is $0.1 \mathrm{~L}$.

\section{Data Availability}

The data, models, or code generated or used during the study are included within the submitted article.

\section{Conflicts of Interest}

The authors declare that they have no conflicts of interest.

\section{Acknowledgments}

This research was sponsored by the Science and Technology Program of Shaanxi and Yunnan Provincial Department of
Transportation (grant no. HMDDGC-D-03). The authors are grateful for the financial support.

\section{References}

[1] S. Chen, "Experimental study of prestressed steel-concrete composite beams with external tendons for negative moments," Journal of Constructional Steel Research, vol. 61, no. 12, pp. 1613-1630, 2005.

[2] H.-K. Ryu, S.-P. Chang, Y.-J. Kim, and B.-S. Kim, "Crack control of a steel and concrete composite plate girder with prefabricated slabs under hogging moments," Engineering Structures, vol. 27, no. 11, pp. 1613-1624, 2005.

[3] M. S. Alfarabi, A. S. Mohammad, K. A. Abul, and H. B. Mohammed, "Use of CFRP to maintain composite action for continuous steel-concrete composite girders," Journal of Composites for Construction, vol. 20, no. 4, Article ID 4015088, 2016.

[4] C. E. Chalioris and P. A. Thomas, "Flexural analysis of steel fibre-reinforced concrete members," Computers and Concrete, vol. 22, pp. 11-25, 2018.

[5] C. E. Chalioris, P. K. Kosmidou, and C. G. Karayannis, "Cyclic response of steel fiber reinforced concrete slender beams; an experimental study," Materials, vol. 12, no. 9, p. 1398, 2019.

[6] V. K. Kytinou, C. E. Chalioris, and C. G. Karayannis, "Analysis of residual flexural stiffness of steel fiber-reinforced concrete beams with steel reinforcement," Materials, vol. 13, no. 12, p. 2698, 2020.

[7] Y. Zhang, Y. Zhu, M. Yeseta et al., "Flexural behaviors and capacity prediction on damaged reinforcement concrete (RC) bridge deck strengthened by ultra-high performance concrete (UHPC) layer," Construction and Building Materials, vol. 215, pp. 347-359, 2019.

[8] Y. Zhu, Y. Zhang, H. H. Hussein, and G. Chen, "Numerical modeling for damaged reinforced concrete slab strengthened by ultra-high performance concrete (UHPC) layer," Engineering Structures, vol. 209, Article ID 110031, 2020.

[9] A. Rafiee, Computer Modeling and Investigation on the Steel Corrosion in Cracked Ultra High Performance Concrete, University of Kassel, Kassel, Germany, 2012.

[10] P. Baltay and A. Gjelsvik, "Coefficient of friction for steel on concrete at high normal stress," Journal of Materials in Civil Engineering, vol. 2, no. 1, pp. 46-49, 1990.

[11] B. Shan, "Experimental study on basic mechanical properties of reactive power concrete," Master thesis, Hunan University, Changsha, China, 2002, in Chinese.

[12] Z. Zhang, X. D. Shao, W. G. Li, P. Zhu, and H. Chen, "Anxial tensile behavior test of ultra high performance concrete," China Journal of Highway and Transport, vol. 28, no. 8, pp. 50-58, 2015, in Chinese.

[13] L. F. Li, X. Fan, X. W. Shi, and X. D. Shao, "Experimental study on flexural behavior of large-scale prestressed UHPC T-shaped beam," China Civil Engineering Journal, vol. 51, no. 5 , pp. 84-94, 2018, in Chinese.

[14] ABAQUS Inc, ABAQUS Theory Manual, Version 6.13, ABAQUS Inc, Palo Alto, CA, USA, 2014.

[15] J. H. Cao, "Research on basic performance of steel-thin UHPC lightweight composite deck" Ph.D thesis, Hunan University, Changsha, China, 2016, in Chinese.

[16] B. Graybeal, Material Property Characterization of Ultra-high Performance concrete. FHWA-HRT-06-103, Mclean: Federal Highway Administration, Washington, DC, USA, 2006.

[17] AFNOR, NF P 18-710 National Addition to Eurocode2-Design of Concrete Structures: Specific Rules for Ultrahigh 
Performance Fibre-Reinforced Concrete, UHPFRC, Paris, France, 2016.

[18] JSCE, Recommendations for Design and Construction of Ultrahigh Strength Fiber Reinforced Concrete Structures, Japan Society of Civil Engineers, Tokyo, Japan, 2006.

[19] MCS-EPFL, Ultra-high Performance Fibre Reinforced Cement Based composites(UHPFRC): Construction Material, Dimensioning and application, Switzerland Swiss Federal Insitute of Technology, Zurich, Switzerland, 2016.

[20] FHWA, Material Property Characterization of Ultra-high Performance Concrete, US Department of Transportation, Federal Highway Administration, Washington, DC, USA, 2006.

[21] Z. Y. Huang and G. Q. Hu, "Research on the shrinkage performance of ultra high performance concrete during heat curing," Materials Review, vol. 30, no. 2, pp. 115-120, 2016, in Chinese.

[22] L. M. Wu, C. J. Wu, Z. H. Zhang, and H. Wang, "Effects of steel fiber on drying shrinkage of ultra high performance concrete," Materials Review, vol. 31, no. 12, pp. 58-65, 2017, in Chinese.

[23] T. Leutbecher and E. Fehling, "Tensile behavior of ultra-highperformance concrete reinforced with reinforcing bars and fibers: minimizing fiber content," ACI Structural Journal, vol. 109, no. 2, pp. 253-264, 2012.

[24] B. Chen, "Research and experiment on bending behavior of wet joints in lightweight composite deck system composed of orthotropic steel and UHPC layer" Ph.D thesis, Hunan University, Changsha, China, 2018, in Chinese. 